\title{
Rádio comunitária construindo o capital social: mulheres rurais na produção radiofônica*
}

Ivanice Oliveira de Lima

Radialista, mestre em Extensão Rural e Desenvolvimento Local e professora do Curso de Comunicação Social da Faculdade Joaquim Nabuco (FJN).

E-mail: nicelima.com@gmail.com

Maria Salett Tauk Santos

Jornalista, doutora em Ciências da Comunicação, coordenadora do Programa de PósGraduaşão em Extensão Rural e Desenvolvimento Local da Universidade Federal Rural de Pernambuco (UFRPE).

E-mail: mstauk@terra.com.br

Resumo: $O$ estudo analisa a produção da Rádio Comunitária Alternativa FM pelas mulheres envolvidas nas ações da organização não governamental Associação das Mulheres de Nazaré da Mata - Amunam. O foco da análise é a contribuição da Rádio Alternativa FM para o desenvolvimento do capital humano e do capital social dessas mulheres. Essa emissora relaciona-se à construção do capital humano por meio de um esforço educativo na formação técnica das mulheres radialistas, assim como ao capital social, na medida em que o trabalho na rádio incentiva a colaboração e a participação política.

Palavras-chave: Rádio comunitária, capital social, mulheres rurais.
Abstract: The study analyzes the production of the Alternativa FM Communitarian Radio by the women involved in the actions of the non-governmental organization Nazaré da Mata Women Association - Amunam. The focus is how Alternativa FM contributes for the development of the human and social capitals of these women. This Radio Station is related to the human capital construction, through an educational effort in the female broadcaster's technical abilities formation; and the social capital's, as the work in the radio station stimulates contribution and political participation of these women who are involved in the radio practice.

Keywords: Communitarian radio station, social capital, rural women.

\section{RÁDIO COMUNITÁRIA: CAPITAL HUMANO, CAPITAL SOCIAL}

O rádio comunitário aparece como um veículo capaz de articular os atores locais na produção de conteúdos e no acesso à informação para a melhoria da qualidade de vida de uma comunidade. O veículo é considerado de fundamental importância na reconfiguração da esfera pública, por possibilitar a abertura da "expressão e participação de setores marginalizados das novas tecnologias de

Recebido em: 22/08/2010

Aprovado em: 17/06/2011

* Artigo extraído da pesquisa Rádio Comunitária, Gênero e Capital Social: a experiência da Alternativa FM, emissora da Associação das Mulheres de Nazaré da Mata Amunam. Dissertação de mestrado de Ivanice Oliveira de Lima para o Programa em Extensão Rural e Desenvolvimento Local da Universidade Federal Rural de Pernambuco, sob a orientação da Professora Doutora Maria Salett Tauk Santos. 
1. BAHIA, Lílian Mourão. Rádios comunitárias: mobilização social e cidadania na reconfiguração da esfera pública. Belo Horizonte: Autêntica Editora, 2008.

2. PERUZZO, Cicilia Krohling. Comunicação nos movimentos populares: a participação na construção da cidadania. Petrópolis: Vozes, 1998.

3. JARA, Carlos Julio. As dimensões intangíveis do desenvolvimento sustentável. Brasília: Instituto Interamericano de Cooperação para a Agricultura - IICA, 2001. p. 99-121.

4. Ibid

5. PERUZZO, Cicilia Krohling. Comunicação nos movimentos populares, cit. comunicação \& educação • Ano XVII • número 1 • jan/jun 2012

comunicação e informação"1. A rádio comunitária favorece a democratização da comunicação, não tem fins lucrativos, oferece programação vinculada à comunidade em que está inserida, valoriza a cultura local e tem compromisso com a cidadania ${ }^{2}$.

A prática do trabalho em grupo nas comunidades e a capacitação de novos agentes produtores de conteúdo, habilitados nas práticas radiofônicas, se relacionam à produção do capital humano e do capital social - dois tipos de capital inseparáveis e complementares, livres de hierarquia entre si.

O capital humano corresponde aos recursos humanos em condições de resolver com adequação e eficácia a diversidade de problemas colocados pela sociedade e com capacidade de empreender processos produtivos integradores e equitativos. [...] O capital social estrutura-se na capacidade de auto-organização, com vínculos solidários, colaboração horizontal, canais de participação, instituições e organizações que estimulam a confiança e a reciprocidade nos relacionamentos entre grupos e atores sociais ${ }^{3}$.

Destacam-se algumas características do rádio comunitário que o aproximam do capital social, dentre as quais: a apropriação das técnicas radiofônicas por atores da localidade; a conquista de espaços dessas emissoras nos meios massivos, através de organização e luta; e a conquista da cidadania a partir da participação política da comunidade, utilizando o rádio como ferramenta para articulação.

Quando pessoas se articulam no sentido de descobrir as causas dos problemas de uma comunidade e propõem alternativas para superá-los, favorece-se o desenvolvimento local ${ }^{4}$. Esse aprendizado constitui a aquisição do capital social e torna-se importante para a superação das situações de pobreza e exclusão social.

Alguns aspectos concorrem para a legitimação das rádios comunitárias como veículos a serviço das comunidades pobres, tais como: a) diversificação dos instrumentos utilizados nas emissoras, de acordo com a disponibilidade dos recursos financeiros, materiais e de tempo; b) apropriação dos meios e técnicas radiofônicos pelos atores da comunidade; c) conquista de espaços nos meios massivos e, em muitos casos, concessão oficial de funcionamento; d) abordagem crítica dos assuntos; e) prevalência de autonomia institucional em relação às instituições privadas e públicas, o que permite independência na divulgação dos conteúdos e na sustentação técnica e financeira; f) abordagem de temas locais relacionados à comunidade; g) veiculação de programas que servem como registro e preservação da memória dos segmentos subalternos; $h$ ) democratização dos meios, possibilitando a participação de um maior número de pessoas; i) conquista da cidadania através de participação política, buscando garantir melhorias para uma determinada população ${ }^{5}$.

O rádio comunitário, portanto, pode servir para amenizar os problemas relacionados à pobreza em que grande parte dos grupos populares se encontra envolvida. Nesses grupos se verifica um contingente que sofre, de maneira mais sensível, os impactos do acesso difícil à saúde, educação, moradia, emprego, cultura: são as mulheres as mais prejudicadas com a pobreza. Por isso, a 
temática da feminização da pobreza vem ganhando maior repercussão ao longo dos anos, mesmo com o crescimento da inserção feminina na esfera pública. O termo feminização da pobreza é utilizado para se referir ao conjunto de aspectos que dizem respeito aos fatores que afetam de maneira diferencial a mulher, à quantidade maior de mulheres entre os pobres e à tendência a um aumento da pobreza feminina.

É no enfrentamento da pobreza da população feminina, marcada por situações de violência simbólica, física, vulnerabilidade familiar e financeira, além da pouca inserção social e política, que atua a Rádio Alternativa FM, em Nazaré da Mata, Pernambuco. Envolvendo as mulheres de contextos populares rurais, a Rádio Alternativa FM desenvolve um trabalho voltado à diminuição dos efeitos negativos da pobreza e exclusão social na população feminina, baseada no entendimento de que a produção radiofônica serve como um estímulo para que elas questionem sua forma de ser e de pensar; incrementem sua capacidade comunicativa; ampliem a visão de mundo; valorizarem-se como pessoas e como

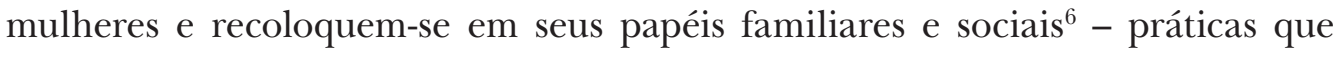
se relacionam à formação de capital humano e de capital social em contextos de pobreza.

A partir da problemática exposta, o objetivo principal deste artigo é analisar a produção da Rádio Comunitária Alternativa FM pelas mulheres envolvidas nas ações da organização não governamental Associação das Mulheres de Nazaré da Mata - Amunam, em Pernambuco. Especificamente, o que se quer compreender é de que forma o trabalho na produção de uma rádio comunitária contribui para o desenvolvimento do capital humano e do capital social dessas mulheres.

\section{A PESQUISA}

Trata-se de um estudo de caso utilizando técnicas combinadas de coleta de dados, como pesquisa bibliográfica, análise documental e entrevista semiestruturada, com a direção e coordenação da Alternativa FM e com mulheres radialistas dessa emissora.

Para fins de análise, as respostas obtidas dos roteiros de entrevistas semiestruturadas foram categorizadas em temas, associando o rádio comunitário ao capital humano, ao capital social e às aspirações das radialistas para o futuro. Na categoria mulheres radialistas e capital humano, analisamos o conhecimento da proposta da Associação das Mulheres de Nazaré da Mata pelas entrevistadas e suas habilidades técnicas no rádio, a fim de observar de que forma está se dando a construção do capital humano através da experiência de atuação na Rádio Comunitária Alternativa FM. Na categoria mulheres radialistas e capital social, observamos o empoderamento e a participação política das mulheres radialistas com a finalidade de perceber como é construído o capital social entre elas. E, por fim, na categoria mulheres radialistas e aspirações para o futuro, procura-se verificar a sustentabilidade das propostas da Amunam via Alternativa FM, relacionando-as aos projetos profissionais das mulheres envolvidas no Projeto.
6. MATA, Maria Cristina. Mulher e rádio popular. São Paulo: Paulinas, 1997 (Coleção Manuais de comunicação, n. 11). 
comunicação \& educação • Ano XVII • número 1 • jan/jun 2012

\section{NAZARÉ DA MATA E AS MULHERES RADIALISTAS}

Nazaré da Mata está situada na região da Zona da Mata Norte de Pernambuco. São pouco mais de $30 \mathrm{mil}$ habitantes distribuídos num território de $150,816 \mathrm{~km}^{2}$. A base econômica da cidade é a produção de cana-de-açúcar. Destacam-se também a avicultura, as indústrias cerâmicas, a indústria alimentícia nos ramos de biscoitos, pães e massas, e o turismo cultural rural ${ }^{7}$, impulsionado pela tradição que o município detém na arte dos Maracatus de Baque Solto, grupos folclóricos típicos do carnaval da zona canavieira de Pernambuco.

A atividade laboral na produção açucareira ao longo dos anos gerou marcas na organização social na Zona da Mata pernambucana. Não é à toa que ainda estão presentes as marcas dessa sociedade patriarcal, exemplificadas pela posição que as mulheres ocupam, com poucas opções de colocação profissional e de dependência financeira do pai ou do marido. Há, entretanto, situações de mulheres que assumem sozinhas a responsabilidade pela casa e pelos filhos. Em Nazaré da Mata, a população feminina é de $51 \%$. Dessas mulheres, $4,04 \%$ são mães, chefes de família que sustentam, sem cônjuge, filhos menores de 15 anos de idade. Além disso, $6,51 \%$ das mulheres de 15 a 17 anos no município já têm filhos ${ }^{8}$.

É nessa realidade de poucas oportunidades para as mulheres que estão inseridas as radialistas da Alternativa FM. Suas famílias mantêm uma ligação direta ou indireta com atividades agrícolas, o que revela que as práticas rurais ainda estão muito presentes na população do estudo. Aos poucos, as mulheres do município vêm conseguindo trabalhos em iniciativas do terceiro setor e o acesso à educação também se tem tornado um pouco mais fácil. Das radialistas entrevistadas, por exemplo, há aquelas que estão cursando ou já concluíram o Ensino Médio e outras que cursam o Ensino Superior, mas não na área de comunicação social.

As oportunidades de trabalho vêm surgindo, como acontece na Alternativa FM, mesmo considerando que a remuneração (em forma de bolsas de auxílio) não seja plenamente suficiente para o sustento de suas famílias. Apesar de o trabalho como radialista não representar uma aferição importante de renda, há de se considerar que o trabalho na rádio possibilita o aprendizado, a socialização e perspectivas de melhoria de vida para essas mulheres.

Das quinze pessoas que trabalham na Alternativa FM, dez são mulheres que participam ou já integraram projetos sociais da Amunam. Elas têm entre 16 e 28 anos e são as responsáveis pelas funções de recepção, operação de áudio, produção e apresentação de programas. Os trabalhos técnicos são realizados sem uma capacitação profissional específica e os métodos de produção e operação do rádio são transmitidos das profissionais que estão há mais tempo na emissora às radialistas novatas.

tentável. Nazaré da Mata:

a Prefeitura, 2003

8. CONDEPE; FIDEM Dados e informações: perfil municipal de Nazaré da Mata. Disponível em: <http:// www.portais.pe.gov. br/c/portal/layout?p_I_ $\mathrm{id}=$ pub.1557.57>. Acesso em: 11 maio 2009

\section{A RÁDIO COMUNITÁRIA ALTERNATIVA FM}

A Alternativa FM é um dos principais projetos desenvolvidos na Associação das Mulheres de Nazaré da Mata. A Amunam foi fundada em 23 de janeiro de 1988 no Sindicato dos Trabalhadores Rurais de Nazaré da Mata, Tracunhaém e 
Buenos Aires. Graças às parcerias com grupos das iniciativas público e privada, a ONG desenvolve oito projetos sociais com crianças, jovens e mulheres adultas em situação de vulnerabilidade social.

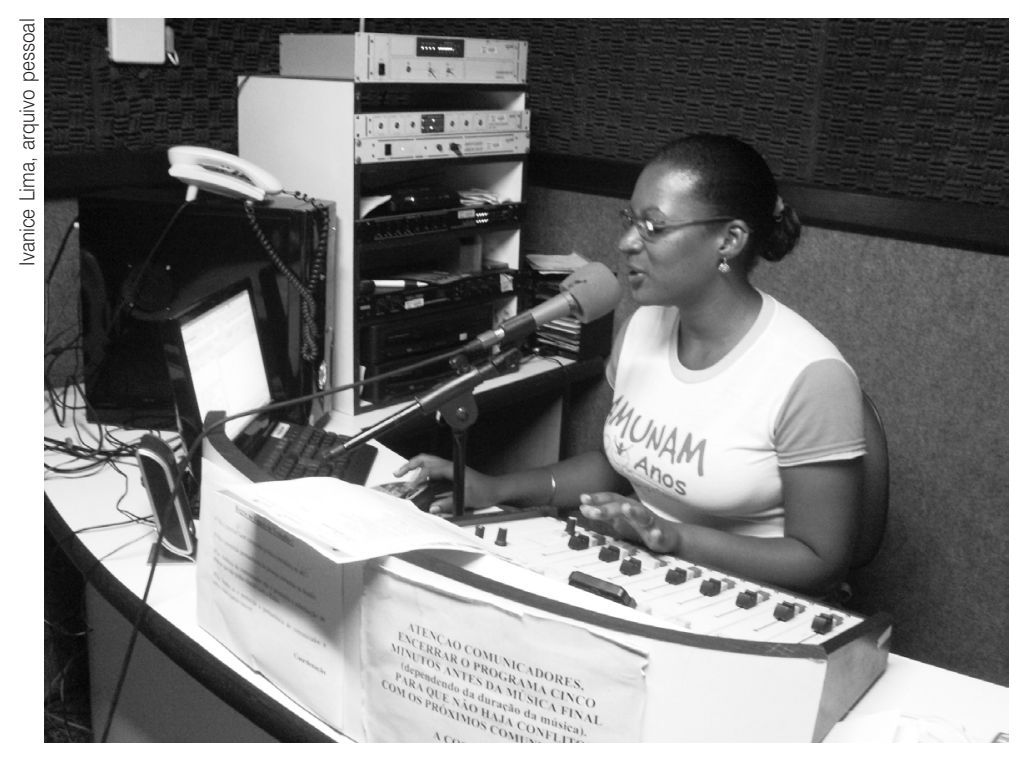

Rádio Comunitária: Ivanice Lima, locutora da Alternativa FM.

A emissora comunitária Alternativa FM opera nos 104,9 MHz com 25 watts de potência, o máximo permitido pela Legislação Brasileira de Radiodifusão Comunitária. A estimativa de audiência é de 12 mil ouvintes na cidade de Nazaré da Mata, e em alguns pontos das cidades vizinhas de Buenos Aires e Itaquitinga. São os apoios culturais que proveem a maior parte dos recursos financeiros responsáveis pelos pagamentos de bolsas mensais de prestação de serviço às mulheres radialistas e aos colaboradores externos à Amunam.

O foco de atuação da Alternativa FM é difundir as temáticas de interesse dos contextos femininos populares - criação dos filhos, sexualidade, participação política, emprego, saúde, moradia, segurança, educação e cultura. Também faz parte da proposta da emissora estimular o desenvolvimento em comunicação, direitos humanos, reivindicação de direitos e a prática dos deveres, buscando envolver a comunidade de Nazaré da Mata nas questões sociais ${ }^{9}$.

Se, de um lado, Rádio Alternativa FM representa um projeto que favorece a construção do capital humano e social, aferição de renda, profissionalização e melhoria de vida das mulheres da comunidade local, por outro lado, constitui um forte desafio para essas mulheres de contextos rurais, marcados pela contingência, atuarem como radialistas.

\section{MULHERES RADIALISTAS E CAPITAL HUMANO}

Ela trabalha com crianças, adolescentes, mulheres, jovens e sempre capacitando, desenvolvendo. Dá aulas para as crianças, capoeira, aula de computação (Entrevistada 5).

9. AMUNAM. Currículo Institucional. Nazaré da Mata: Amunam, 2009. 
comunicação \& educação • Ano XVII • número 1 • jan/jun 2012

De acordo com este depoimento de uma das radialistas entrevistada a respeito do conhecimento sobre a proposta da Associação das Mulheres de Nazaré da Mata, percebe-se que as mulheres conhecem as características gerais da Amunam, entretanto, demonstram desconhecer questões referentes a ingerências políticas da entidade, detalhes sobre parcerias sociais ou informações mais precisas a respeito da sustentação financeira da Associação e das atividades desenvolvidas por ela, o que indica que o capital humano ainda está em formação.

Sobre as habilidades técnicas desenvolvidas com a prática radiofônica:

Chego lá, ligo, opero, boto as músicas no ar, solto tudo. Além de ser uma atividade nova que eu tô aprendendo, tô levando conhecimento às pessoas através do rádio (Entrevistada 3).

Depois que eu vim para a Alternativa, as pessoas começaram a me procurar para fazer gravação. Foi valorizado o meu trabalho (Entrevistada 4).

Pode-se inferir que as habilidades técnicas desenvolvidas pelas mulheres na Rádio Comunitária Alternativa FM são, em grande parte, responsáveis pela geração de capital humano nessas jovens. Isso pelo fato de, dia após dia, conhecimentos serem gerados num trabalho conjunto, possibilitando uma gradual apropriação das técnicas do rádio pelas mulheres e o desenvolvimento de perspectivas profissionais.

\section{MULHERES RADIALISTAS E CAPITAL SOCIAL}

Os trabalhos na Rádio que geram comprometimento e cooperação são expressões de solidariedade que favorecem a construção do capital social entre as radialistas, conforme se observa a partir dos depoimentos:

A gente aqui se entende, sempre que alguém tá precisando de alguma ajuda, a gente sempre tá lá (Entrevistada 5).

A parceria é fundamental aqui. Você não faz só uma coisa, quando você tá fazendo uma determinada atividade, chega outra pra você fazer (Entrevistada 4).

Ao mesmo tempo, o exercício profissional no rádio possibilita que as mulheres se sintam mais "empoderadas", condição fundamental para o desenvolvimento do capital social, como evidenciam os relatos:

A cada programa a gente vai se atualizando e aprendendo (Entrevistada 3).

Isso [o trabalho no rádio] aumenta mais a sua autoestima, a sua vontade de trabalhar, de fazer o melhor possível (Entrevistada 4).

A partir do "empoderamento" gerado dos trabalhos na Alternativa FM, é possível inferir que as mulheres tornam-se muito mais capacitadas profissionalmente e donas de seus próprios projetos de vida, uma vez que têm despertadas habilidades que algumas delas não tinham consciência de que possuíam.

Outra característica surgida a partir das atividades na Rádio foi a representação das mulheres radialistas em vários espaços de poder. Embora não se verifique ainda, entre as entrevistadas, uma prática recorrente de organização 
Rádio comunitária construindo o capital social - Ivanice O. de Lima e Maria S. T. Santos

econômico-produtiva de representação de classe ou sindical, a maior parte das envolvidas nos trabalhos na Alternativa FM, de forma direta ou indireta, acaba tendo participação nos espaços (congressos, seminários, conferências) onde são tratados temas de interesse da Amunam ou da emissora comunitária da Associação, e se articula com diferentes grupos de várias partes do Brasil:

Essa é a coisa que eu mais gosto: me articular com outras pessoas para adquirir mais conhecimento e pôr em prática aqui as coisas boas que a gente encontra lá fora (Entrevistada 4).

Essa inserção política está intimamente relacionada à construção do capital social das mulheres da Alternativa FM, uma vez que são proporcionados conhecimentos e relacionamentos sociais que interferem na vida social e política delas enquanto profissionais de rádio.

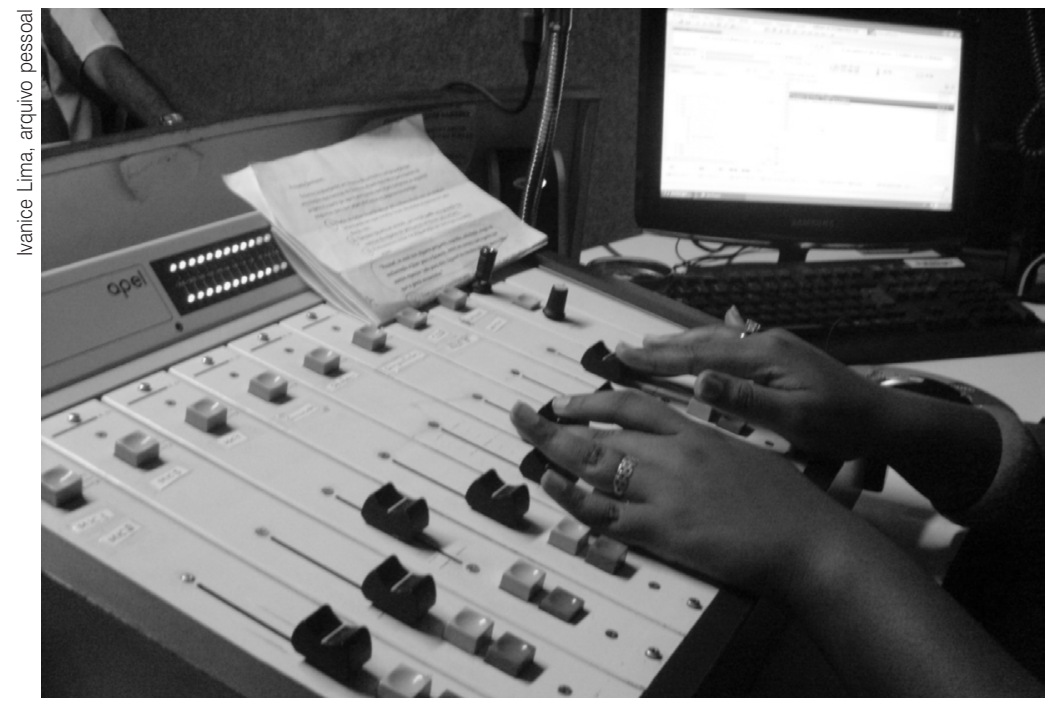

Rádio Comunitária: Ivanice Lima operando a mesa de áudio.

\section{MULHERES RADIALISTAS E ASPIRAÇÕES PARA O FUTURO}

Os depoimentos mostram que, embora algumas entrevistadas tenham o rádio como projeto profissional, nem todas pretendem seguir carreira na área:

Eu pretendo fazer um curso técnico em análises clínicas. Se eu não conseguir, eu pretendo fazer a faculdade para História (Entrevistada 3).

O que eu queria, de verdade, era fazer a minha faculdade de Rádio e TV. É o que eu mais quero na minha vida (Entrevistada 4).

Independentemente do desejo de seguir carreira no rádio, há de considerar que, em qualquer área profissional, deve existir boa comunicação e bom predomínio de capital social, incentivado a partir das experiências atuais das mulheres na Rádio Comunitária. Esse capital social gerado - e em franca evolução - habilita as radialistas a desenvolverem participação ativa em várias áreas, e não somente no rádio. 
comunicação \& educação • Ano XVII • número 1 • jan/jun 2012

\section{CONSIDERAÇÕES FINAIS}

A Rádio Comunitária Alternativa FM, ao empreender um trabalho de comunicação tendo os contextos populares como protagonistas das ações, proporciona o desenvolvimento individual e coletivo desses atores. A emissora realiza um projeto voltado à construção do capital humano, ao possibilitar formação e desenvolvimento de habilidades técnicas pelas radialistas - capacitação que favorece a aferição de renda e a tentativa de superação de dificuldades financeiras das mulheres de contextos populares, nesses contingentes especialmente marcados pela pobreza. A construção do capital social se dá à medida que o trabalho na rádio incentiva a colaboração e a participação política dessas mulheres envolvidas na prática radiofônica. Embora esses capitais humano e social ainda estejam em formação e façam parte de um processo que não se estabelece de forma repentina, há de se considerar que, para as mulheres de contexto rural, eles se configuram em importantes fatores capazes de ampliar as perspectivas profissionais e pessoais delas. O que fortalece a tese de que o rádio comunitário é um importante meio para a construção dos capitais humano e social, na medida em que é capaz de gerar renda para a população envolvida na produção radiofônica, contribuir para o empoderamento e a organização política das mulheres do campo, na perspectiva do enfrentamento da pobreza e da exclusão das mulheres dos contextos populares rurais.

\section{REFERÊNCIAS BIBLIOGRÁFICAS}

AGENDA 21. Nazaré da Mata 2004: no caminho de desenvolvimento sustentável. Nazaré da Mata: Prefeitura, 2003.

AMUNAM. Currículo Institucional. Nazaré da Mata: Amunam, 2009.

BAHIA, Lílian Mourão. Rádios comunitárias: mobilização social e cidadania na reconfiguração da esfera pública. Belo Horizonte: Autêntica Editora, 2008.

JARA, Carlos Julio. As dimensões intangíveis do desenvolvimento sustentável. Brasília: Instituto Interamericano de Cooperação para a Agricultura - IICA, 2001.

MATA, Maria Cristina. Mulher e rádio popular. São Paulo: Paulinas, 1997.

PERUZZO, Cicilia Krohling. Comunicação nos movimentos populares: a participação na construção da cidadania. Petrópolis: Vozes, 1998.

\section{Endereços eletrônicos}

CONDEPE; FIDEM. Dados e informações: perfil municipal de Nazaré da Mata. Disponível em: <http://www.portais.pe.gov.br/c/portal/layout?p_l_ $\mathrm{id}=$ pub.1557.57>. Acesso em: 11 maio 2009. 